\section{Single-switch soft-switching flyback converter}

\section{J.-B. Lio, M.-S. Lin, D.Y. Chen and W.-S. Feng}

Indexing terms: Power convertors, DC-DC power converters

A novel control method is proposed to achieve soft-switching in the single-switch flyback converter. Using the proposed scheme, circuit efficiency is increased while the simplicity of the circuit is maintained. A $200 \mathrm{~W}$ converter is built to verify the proposed scheme.

Introduction: In low-power DC-to-DC applications, flyback converters are widely used because of circuit simplicity. Many softswitched techniques have been proposed for flyback converters $\left[\begin{array}{ll}1 & -5\end{array}\right]$. These techniques are classified into two categories: the quasi-resonant technique (QRT) [1,2], and the active-clamp technique (ACT) [3 - 5]. In the QRT, device switching losses are reduced only at the expense of much increased voltage/current stresses of the switches. This may not lead to a significant reduction in total losses, and in fact in some cases the total losses may increase as compared with a hard-switching converter. In the ACT, the overall losses are significantly reduced, but the technique requires the use of two active power switches, often resulting in control circuit complexity and often an unacceptable cost increase. In this Letter a new soft-switching flyback converter is proposed in which soft-switching can be achieved without increasing the voltage/current stresses of the switches, and at the same time only one active switch is required. Table 1 shows a comparison of the features of the proposed soft-switching scheme with conventional schemes.

Table 1: Comparison of features of proposed soft-switching scheme with conventional schemes

\begin{tabular}{|c|c|c|c|c|}
\hline Converters & $\begin{array}{c}\text { Conduction } \\
\text { loss }\end{array}$ & $\begin{array}{c}\text { Switching } \\
\text { loss }\end{array}$ & $\begin{array}{c}\text { Numbers of } \\
\text { power } \\
\text { switches }\end{array}$ & $\begin{array}{c}\text { Switching } \\
\text { frequency } \\
\text { characteristics }\end{array}$ \\
\hline QRT [1,2] & high & low & 1 & variable \\
\hline ACT [3-5] & low & low & 2 & constant \\
\hline Proposed scheme & low & low & 1 & variable \\
\hline
\end{tabular}

In this Letter a description of the operation of the circuit is given, and then experimental results obtained from the circuit hardware are presented.

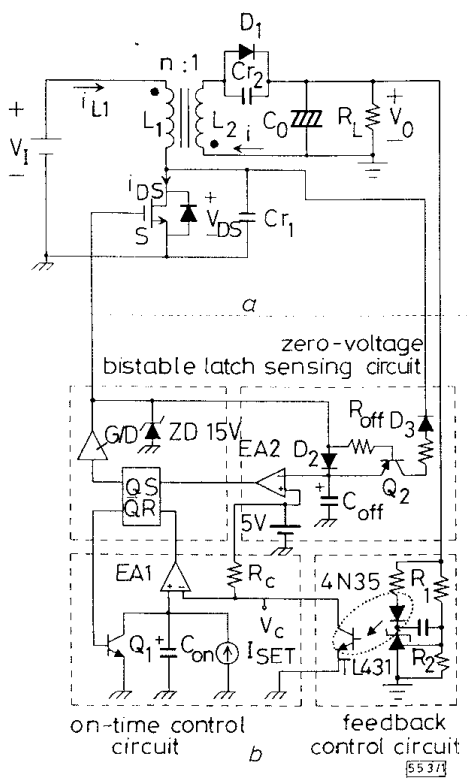

Fig. 1 Proposed flyback converter

a Power stage

$b$ Control function of on-time control
Circuit description: The proposed soft-switching scheme involves a slight modification of the basic flyback configuration and a novel control scheme. Referring to Fig. 1, two resonant capacitors $C_{r_{1}}$ and $\mathrm{Cr}_{2}$ are added to the power circuit to achieve zero-voltage turn-on (ZVS) of the main switch S, eliminating the turn-on loss of S. Capacitors $\mathrm{Cr}_{1}$ and $\mathrm{Cr}_{2}$ also serve as a lossless snubber at turn-off. The control circuit consists of four major blocks: feedback circuit, bistable latch, zero-voltage sensing circuit and ontime control circuit. The feedback control circuit consists of an opto-isolator and a regulator TL431. This circuit is used to regulate the output voltage and is similar to a conventional feedback circuit. The bistable latch is used to latch the control signal to drive the main switch $\mathrm{S}$. The ZVS sensing circuit is used to sense the $V_{D S}$ of $\mathrm{S}$ and issue a tum-on signal to achieve the ZVS of $\mathrm{S}$. The power converter must be operated at discontinuous mode to achieve ZVS. The on-time control circuit determines the on-time of $\mathrm{S}$ to control the output power $P_{o}$. The operation of the overall circuit is described in detail below.

$t_{0}-t_{1}$ (on period): The on period starts when $\mathrm{S}$ is turned on. The input voltage $V_{Y}$ is applied across the transformer primary and the transformer core flux increases linearly from zero. The voltage $V_{c o n}$ in the on-time control circuit increases linearly with time as the charging current $I_{S E T}$ charges $C_{o n}$ until $V_{C o n}$ reaches the control voltage $V_{c}$. When that happens, $\mathrm{S}$ is turned off. As $C r_{1}$ serves as a snubber while $\mathrm{S}$ turns off, the turn-off losses are minimal. The ontime $t_{m n}$ is determined by

$$
t_{o n} \simeq \frac{V_{c} C_{o n}}{I_{S E T}}
$$

where $I_{S E T}$ is a current source which is commonly realised by using a current mirror scheme. Because the maximum value of $V_{C}$ is $5 \mathrm{~V}$, $C_{o n}$ and $I_{S E T}$ predetermine the maximum on-time $t_{o r, m a x}$. The output power transferred can be calculated as follows:

$$
P_{o}=\eta \frac{D t_{o n} V_{I}^{2}}{2 L_{1}}=\eta \frac{D V_{c} C_{o n} V_{I}^{2}}{2 I_{S E T} L_{1}}
$$

where $\eta$ is the circuit efficiency, $D$ is the duty cycle of $\mathrm{S}$ and $L_{1}$ is the transformer magnetiSing inductance.

$t_{1}-t_{2}$ (off period): After $\mathrm{S}$ has been turned off the energy stored in the transformer core is transferred to the output of the converter, and $i_{r 2}$ decreases linearly until it reaches zero at the end of the offinterval and $D_{1}$ is turned off without reverse recovery problems.

$t_{2}-t_{3}$ (resonant period): After $D_{1}$ has been turned off, $C r_{1}, C r_{2}$ begin to resonate with $L_{1}$ and $L_{1}$, and $V_{D S}$ decreases. To ensure that $V_{D S}$ can reach zero voltage at the end of this period, the following inequality must be met:

$$
n V_{o}>V_{I}
$$

where $n$ is the transformer turns ratio. As $V_{D S}$ falls below $5 \mathrm{~V}, C_{\text {off }}$ (in the ZVS sensing circuit) is discharged through $Q_{2}$ and $D_{3}$, and EA2 sets the output of the bistable latch to high; $S$ is turned on while the body diode of $\mathrm{S}$ is conducting, thereby achieving ZVS.

A sequence of events that explains how output voltage regulation is achieved is now given. If, for some reason, $V_{0}$ is decreased, then TL431 should reduce the bias on opto-isolator 4 N35 which increases $V_{C}$. When $V_{C}$ is increased, the output power increases according to eqn. 2, which pulls $V_{o}$ back to regulation.

During circuit starting, $V$ is too low to meet eqn. 3 , and therefore the ZVS sensing circuit will not issue a signal to turn on $\mathbf{S}$. However, $R_{o f f}$ allows $C_{o f f}$ to be discharged and $\mathrm{S}$ will be turned on although not on ZVS. This feature ensures that the switching cycle continues until $V_{0}$ is large enough to achieve the ZVS condition. From that point on, the ZVS sensing circuit takes over and determines the turn-on of $\mathrm{S}$.

Experimental results: A converter based on the circuit described above was built and tested. The output power at full load was $200 \mathrm{~W}$. The component values used were $L_{1}=100 \mu \mathrm{H}, n=5$, transformer leakage inductor $2.1 \mu \mathrm{H} . C r_{1}$ and $C r_{2}$ are ceramic capacitors, $C r_{1}=3.5 \mathrm{nF}, C r_{2}=140 \mathrm{nF}$, and the switch $\mathrm{S}$ was a MOSFET IRF740. Fig. 2 shows the full load experimental waveforms when 


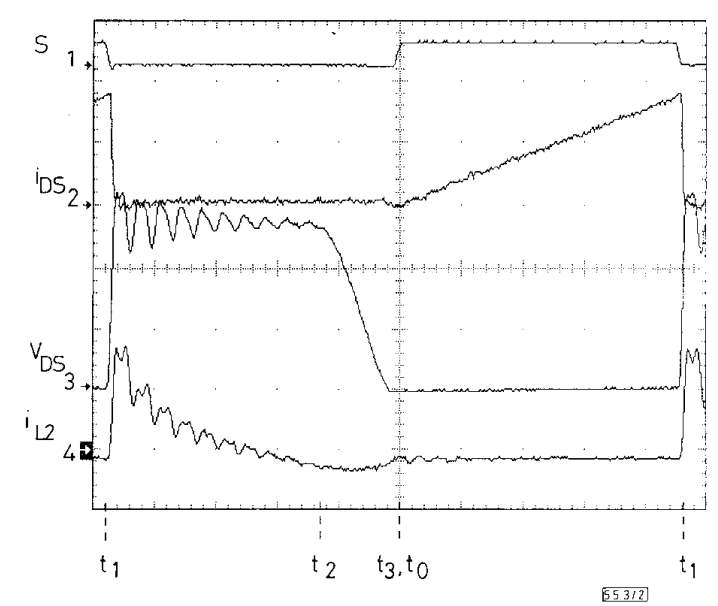

Fig. 2 Experimental waveforms for output power at full load $200 \mathrm{~W}$ Time scale $2 \mu \mathrm{s} / \mathrm{div}$, control signal on $\mathrm{S} 50 \mathrm{~V} / \mathrm{div}, i_{D S} 5 \mathrm{~A} / \mathrm{div}, V_{D S}$ $100 \mathrm{~V} / \mathrm{div}, i_{1,2} 20 \mathrm{~A} / \mathrm{div}$

$V_{l}=120 \mathrm{~V}, V_{a}=30 \mathrm{~V}$, and $R_{L}=4.5 \Omega$; the efficiency of the converter was $90 \%$. The switching frequency varied from $54 \mathrm{kHz}$ at full load to $135 \mathrm{kHz}$ at light load $20 \mathrm{~W}$. From the waveforms of $V_{D S}$ and $i_{L 2}$ in Fig. 2, it is clear that the soft-switching of the switch $\mathrm{S}$ and soft commutation of the output rectifier $D_{1}$ has been achieved, and the switching losses are much reduced. In Fig. 2 the energy stored in the transformer leakage inductance caused only a small voltage overshoot on $V_{D S}$ when $S$ turned off, because this energy was absorbed by $\mathrm{Cr}_{2}$ losslessly, so that the energy transition efficiency through the transformer is high.

Conchusions: By using the proposed soft-switching scheme, the power density and efficiency of a flyback converter can be increased, while retaining the simplicity and low cost of the configuration and the low cost feature are retained. The control circuit can easily be implemented by an integrated circuit

(C) IEE 1996

4 June 1996

Electronics Letters Online No: 19960984

J.-B. Lio, M.-S. Lin and W.-S. Feng (Department of Electrical Engineering, National Taiwan University, Taipei 10617, Taiwan, Republic of China)

D.Y. Chen (Virginia Power Electronics Center, Virginia Polytechnic Institute and State University, USA)

\section{References}

1 RidLey, R.B., LOTFI, A., VORPERIAN, v, and LEe, F.C.: 'Design and control of a full-wave quasi-resonant flyback converter'. IEEE APEC Proceedings, 1988, pp. 41-49

2 TABISZ, W.A., GRADZKI, P.M, and LEE, F.C.: 'Zero-voltage-switched quasi-resonant buck and flyback converters - experimental results at $10 \mathrm{MHz}$ ', IEEE Trans. Power Electron., 1989, 4, (2). pp. 9-17

3 NAGATA, N, and HIROMURA, O.: 'Switching power supply'. US patent $4,958,268,1990$

4 YoshidA, K., ISHII, T., and NAGAGATA, N.: 'Zero voltage switching approach for flyback converter'. Proceedings of the Fourteenth International Telecommunications Energy Conference, 1992, pp. 324.329

5 WATSON, R, LEE, F.C., and HUA, G.C: 'Utilization of an activv-clamp circuit to achieve soft switching in flyback converters'. IEEE PESC Record, 1994, pp. 909-916

\section{Analysis of hemispherical cavity-backed slot antenna}

K.W. Leung and K.Y. Chow

\author{
Indexing terms: Slot antennas, Antennas
}

The input impedance of the hemispherical cavity-backed slot antenna is investigated theoretically and experimentally. The mode-matching method and moment method are used to find the Green's function of the cavity and the equivalent magnetic current of the slot, respectively. The effects of slot length and cavity radius on the input impedance are studied.

Introduction: The slot antenna has several inherent merits such as a low profile, ease of fabrication, and high power capability. A slot cut in an infinite ground plane is easy to analyse by using the Booker relationship [1], but is free to radiate from both sides. Very often, radiation from one side alone is desirable and a metallic cavity is used to block back-side radiation $[2-5]$. This improves the radiation efficiency of the front side.

Studies of the cavity-backed slot antenna have mainly concentrated on rectangular cavities [2 - 4]. Recently, however, a cylindrical cavity-backed slot antenna was studied by $\mathrm{Li}$ et al. theoretically and experimentally [5]. The extension of the cylindrical cavity to the hemispherical version is of interest. In this Letter, the input impedance of the hemispherical cavity-backed slot antenna is calculated and verified by measurement. The Green's function approach [2] is used to formulate the problem, with the Green's function derived rigorously using the mode-matching method [6]. It should be mentioned that when the slot is aligned with the diameter of the cavity, all TM cavity modes are eliminated (provided that the slot is thin enough) and only TE modes remain. In this Letter, the slot is located at the centre of the cavity and aligned with the diameter. Therefore we will consider the cavity's $T E_{111}$ mode, the fundamental TE mode. The equivalent magnetic current in the slot, and hence the input impedance of the antenna, are found using the method of moments (MoM). The effects of the slot length and of the cavity radius on the input impedance are studied.

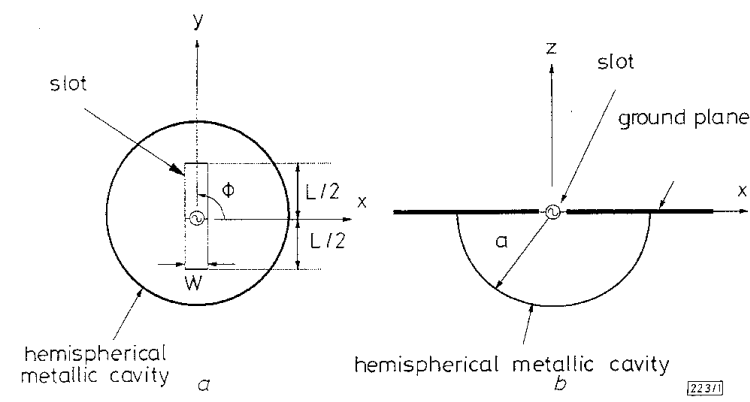

Fig. 1 Geometry of hemispherical cavity-backed slot antenna

a Top view

$b$ Side view

Theory: Fig. 1 shows the geometry of the cavity-backed slot antenna. A slot of length $L$ and of width $W$ is covered on one side by a hemispherical cavity of radius $a$. To begin with, image theory is invoked so that the magnetic field Green's functions in the upper-half plane $\left(G_{l}\right)$ and in the cavity $\left(G_{C}\right)$ can be found separately. Enforcing the boundary condition of the magnetic field across the slot, we obtain the following integral equation:

$$
-2 \iint_{S_{0}}\left[G_{U}\left(\vec{r}, \vec{r}^{\prime}\right)+G_{C}\left(\vec{r}, \vec{r}^{\prime}\right)\right] M_{y}\left(y^{\prime}\right) d S^{\prime}=I_{0} \delta(y)
$$

where $M_{y}$ and $I_{0}$ are the equivalent magnetic current in the slot and the terminal electric current of the voltage source, respectively. $S_{0}$ is the surface of the slot. The Green's function $G_{U}$ has been well-studied and is not repeated here. The Green's function $G_{C}$ is found rigorously using the mode matching method [6]. At frequencies not much higher than the cavity's $T E_{11}$-mode resonance, the singlemode approximation [7] is as follows $\left(z=z^{\prime}=0\right)$ : 